INTERNATIONAL DESIGN CONFERENCE - DESIGN 2018

https://doi.org/10.21278/idc.2018.0437

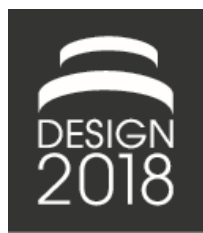

\title{
MODEL-BASED DECISION SUPPORT FOR VALUE AND SUSTAINABILITY ASSESSMENT: APPLYING MACHINE LEARNING IN AEROSPACE PRODUCT DEVELOPMENT
}

\author{
A. Bertoni, S. K. Dasari, S. I. Hallstedt and P. Andersson
}

\begin{abstract}
This paper presents a prescriptive approach toward the integration of value and sustainability models in an automated decision support environment enabled by machine learning (ML). The approach allows the concurrent multidimensional analysis of design cases complementing mechanical simulation results with value and sustainability assessment. ML allows to deal with both qualitative and quantitative data and to create surrogate models for quicker design space exploration. The approach has been developed and preliminary implemented in collaboration with a major aerospace sub-system manufacturer.
\end{abstract}

Keywords: decision making, value driven design, big data analysis, sustainable design, design space exploration

\section{Introduction}

Aircraft development is a long lead time project starting with assumptions of requirements that mature and are adjusted during the projects, according to Set-Based Concurrent Engineering (SBCE) Sobek et al. (1999) approaches. The long lead time creates a challenging situation for sub-system and component manufacturers asked to design new solutions with requirements uncertainty while concurrently aiming at increased design robustness, weight reduction, costs reduction, and product performances within acceptable boundaries. Traditionally Multi-Disciplinary Design Optimization (MDDO) approaches have been used to address the design challenge of considering a rather open set of feasible design solutions rather than focusing on a specific solution point in the design space.

Recently, researchers in the area of Value Driven Design (VDD) and Sustainable Product Development (SPD) have recognised the need to include models for value and sustainability assessment for early design concept evaluation, in order to expand the range of early design analysis to more than product feasibility and technical performances (Ross et al., 2004; Steiner and Harmon, 2009; Bertoni et al., 2015a; Bertoni et al., 2016; Hallstedt, 2017). However, it is still a challenge to model the link between the mechanical performances of a range of design variants, the value generated for the stakeholders and the derived sustainability implications.

The embodiment and assessment of many design variants in early design is increasingly enabled by the application of Knowledge Based Engineering (e.g. Verhagen et al., 2012; Quintana-Amate et al., 2017). Although value and sustainability-related considerations suffer from a critical lack of data to be integrated into automatic systems for design assessment and would benefit from a solution capable of integrating them into the design analysis. Such solution would eventually render a situation in which value and sustainability could be more easily assessed or predicted to support engineering design decision-making. The integration of multidimensional analysis into a unique decision support model has 
been proved to be possible for many different industrial contexts, thanks to the use of Machine learning (ML) techniques and big data analytics (e.g. Akhavian and Behzadan, 2013; Bertoni et al., 2017). However, no application exists yet concerning the integration of value and sustainability assessment models in a combined approach for engineering decision support in early design.

The paper presents a prescriptive approach toward the integration of value and sustainability models in an automated decision support environment enabled by the use of machine learning techniques. The approach aims to support cross-disciplinary decision making in the early design stages and has been developed and preliminary implemented in collaboration with a major aerospace sub-system manufacturer. Its rationale and application are described in the paper through the case study of the design of a new generation Turbine Rear Structure (TRS) for commercial aircraft engines.

\section{Research methodology}

The approach presented in this paper is the result of a research effort that can be framed in the Design Research Methodology (DRM) (Blessing and Chakrabarti, 2009). The work concerns to a large extent the third stage of the methodology, presenting a prescriptive model addressing the previously identified design challenges. The work also includes an implementation of the model in a controlled environment to preliminary evaluate both the model per se and its application environment. The proposed solution builds on previous research clarification and descriptive study concerning issues and challenges on value and sustainability assessment in the area of aerospace product development (findings previously published by Isaksson et al., 2015).

In the frame of the DRM methodology the work has been conducted following an iterative look-thinkact routine (or "learning circles") in which the researchers tested a model with practitioners in real situations, gain feedback from these experiences, modify the model as a result of this feedback, then try again; similar to what described by Avison et al. (1999), and Coughlan and Coghlan (2002).

The approach developed is presented in the paper based on a single case study application, although the problem identification, the requirements definition and the rationale and logic of the prescriptive solution can be generalized to different industrial cases. The data used and visualized in the case study have been partially generated through computer-based simulations and finite element analysis on real design cases, those data were further complemented with realistic but artificial data to avoid issues of industrial secrecy.

\section{Towards the application of machine learning in value driven design and sustainable product development}

Development teams are used to model engineering problems and to use models results for decision making. Finite Element Analysis, Computational Fluid Analysis and Modal Analysis are traditional modelling methods that are applied to evaluate the performances of a concept before initiating its physical development. The integration of less quantifiable or "fuzzy" aspects, such as value and sustainability, in a model-based decision support system introduces, however, a higher level of uncertainty, given by the multidisciplinary nature of the data, embedding qualitative evaluation difficult to be supported by computer-based simulation techniques, since lacking the necessary input data.

In the aerospace industry products have typically a life cycle of many decades. Here design engineers need to understand the multidisciplinary implications of decisions made in early design stages, that will impact lifecycle value and sustainability performances for many decades ahead.

From a VDD perspective, this challenge has high implications in the process of linking stakeholders' needs to technical requirements. Commonly quantitative data are used for the estimation of cost and lead time of specific design solutions. At the same time, qualitative data drive the design analysis for what concerns the assessment of the value of new functions, and for what concerns potential synergies in design, manufacturing or servicing (e.g., customer support, product platform commonalities, scalability of solutions) (Ross et al., 2004; McManus et al., 2007).

From a SPD perspective, there is a need for an improved understanding of how a design solution influence social- and environmental sustainability aspects. To understand that, it is necessary to identify which socio-ecological indicators are relevant for a product throughout its whole lifecycle, i.e. from raw material acquisition to disposal phase. Sustainability should not automatically be seen as negative 
impacts and increased risks but also as an opportunity for designing more sustainable solutions for the product's lifecycle and thereby differentiate from competitors (Schulte and Hallstedt, 2017). Material selection is one example of a design feature that needs to be decided early and has a direct impact on downstream decisions, e.g., the selection of manufacturing processes and end-of-life solutions (Giudice et al., 2005). Unavailability of materials may lead to costly re-investments and re-design of complex products or a deteriorating market. The challenge is to see the connection between short-term and longterm sustainability risks and to understand the connection between sustainability risks and other design variables. The time perspective for the risks is often vague for design teams dealing with products with long life-span. Those need to identify, and possibly quantify, the long-term risks of present choices.

The consequence is the weakness in current decision situations, given by the inability to clarify and understand the "value" and "sustainability" implications compared to, for instance, the mechanical performance of concepts. Models are not available, or mature enough, to integrate those two dimensions into the traditional decision-making models. In other words, design engineers have poor model support to answer questions like: "Which is the most valuable component to develop?" or "How would its sustainability profile looks like?" Questions that need to be answered before committing high resources on a development project. In such scenario, extensive data analysis enabled by machine learning (ML) algorithms comes into play as a possible solution to support the prediction of value and sustainability performances. ML allows the identification of hidden correlations on existing sets of multidisciplinary and multidimensional data, allowing the creation of predictive models that can reduce the uncertainty of decision makers facing the challenge of estimating value and sustainability performances with uncertain and incomplete data. The creation of predictive models, capable of dealing with heterogeneous variables to be integrated into a knowledge-enabled engineering environment, enables the possibility of simulating different complex scenarios with limited consumptions of time and resources, thus allowing a larger exploration of the design space, given the condition of keeping an acceptable degree of reliability. From a ML perspective, this means developing approximation models (also known as response surface models, surrogate models and meta-models (Mack et al., 2007)), allowing engineers to approximate time-consuming simulations by mimicking the complex behaviour of the underlying simulation analysis. Statistical methods such as Kriging and polynomial methods are popular to construct surrogate models dealing with both quantitative and qualitative data, thus eventually capable of including those value and sustainability data non-numerically quantifiable. Furthermore, ML methods such as support vector machines, tree-based models, artificial neural networks and radial basis functions have been used to construct response models in similar cases (e.g. Queipo et al., 2005; Shan and Wang, 2010; Dasari et al., 2015).

The approach using ML as an enabler for value and sustainability assessment in a knowledge-based engineering system addresses the challenges described in this section, thus focusing on the integration of the finding from three research areas, namely SPD, VDD, and ML. Based on the industrial problem description, the state of the art of the research fields, and previous research (Isaksson et al., 2015), three criteria to judge the usability of the described approach have been identified to verify the applicability and effectiveness the proposed approach. Those are:

- Ability to manage value and sustainability issues that are multi-dimensional, often context dependent and difficult to condense into a unified way of modelling.

- Ability to aggregate value and sustainability evaluation, encompassing both qualitative and quantitative data, in a unique model.

- Ability to quantify uncertainty that is hidden behind assumptions used in the evaluation of value, thus not providing a false impression of accuracy in the results.

\section{An integrate scenario for value and sustainability assessment in early design enabled by machine learning}

The approach exemplifying how machine learning can support value and sustainability evaluation in early design is summarized in this section. The section has the double objective of presenting the novel approach for ML application in VDD and SPD and to describe the most recent application of the approach in aerospace product development. The section initially describes the findings related to the definition of the ideal set of value and sustainability criteria identified in the study, and later describes how machine learning has been applied to a subset of them to provide decision making support in early design. 
The example is based on the development of a Turbine Rear Structure (TRS). The TRS is one of the larger static components of an aircraft engine and its main functions are to redirect the outgoing flow and transfer different loads. The design of a TRS is a complex task, and the early design phase includes high level of uncertainty in requirements, rendering an open design space. Consequently, a high number of multi-disciplinary studies is needed, focusing, for instance, on aero performance, mechanical functions, "producibility", together with the value and sustainability assessments. Commonly different studies are run with specific design objectives, where the design engineers simulate specific product features, e.g. engine mount position, number of struts. These studies share a few common design parameters, e.g. thermal zones, even though they are focused on different design objective for the TRS. The analysis of each design objective provides an idea on how design parameters affect the performance of the engine in terms of quality, cost, weight, etc. The challenge is to explore how the various design objectives of the TRS studies relate to each other. This becomes evident when the focus is on understanding how value analysis relates to sustainability assessments and what is the correlations of both of them to the mechanical analysis studies.

\subsection{Definition of value criteria}

The first step of the value modelling activity was to identify the value criteria more relevant for the specific TRS case. The generic definition of families of criteria relevant for aerospace product development has been discussed in a number of publications in the systems engineering literature (Ross et al., 2004; Steiner and Harmon, 2009; Bertoni et al., 2011). Concerning the development of a TRS, a previous work by Bertoni et al. (2015b) has highlighted a framework of reference for value model development encompassing qualitative and quantitative criteria. Such framework has been used as starting point for identifying specific criteria that needed to be quantified in the TRS development example. Figure 1 shows the value criteria identified in the study. The criteria are divided into two main families: those quantifiable numerically encompassing operational performances, production and servicing, and those quantifiable qualitatively, through the use of categorical variables, encompassing "ilities" and "commonality". A critical difference between the two families relies in the context dependency of the methods used for their computation: while quantitative criteria can be computed using numerical functions that are context independent, and thus generalizable (e.g. the cost of raw material does not depend on its final application), qualitative criteria assessment is based on judgement dependant from the specific industrial context in which a new design is developed (e.g. the commonality in technology is dependent from the technology development of a specific company at a specific moment in time).

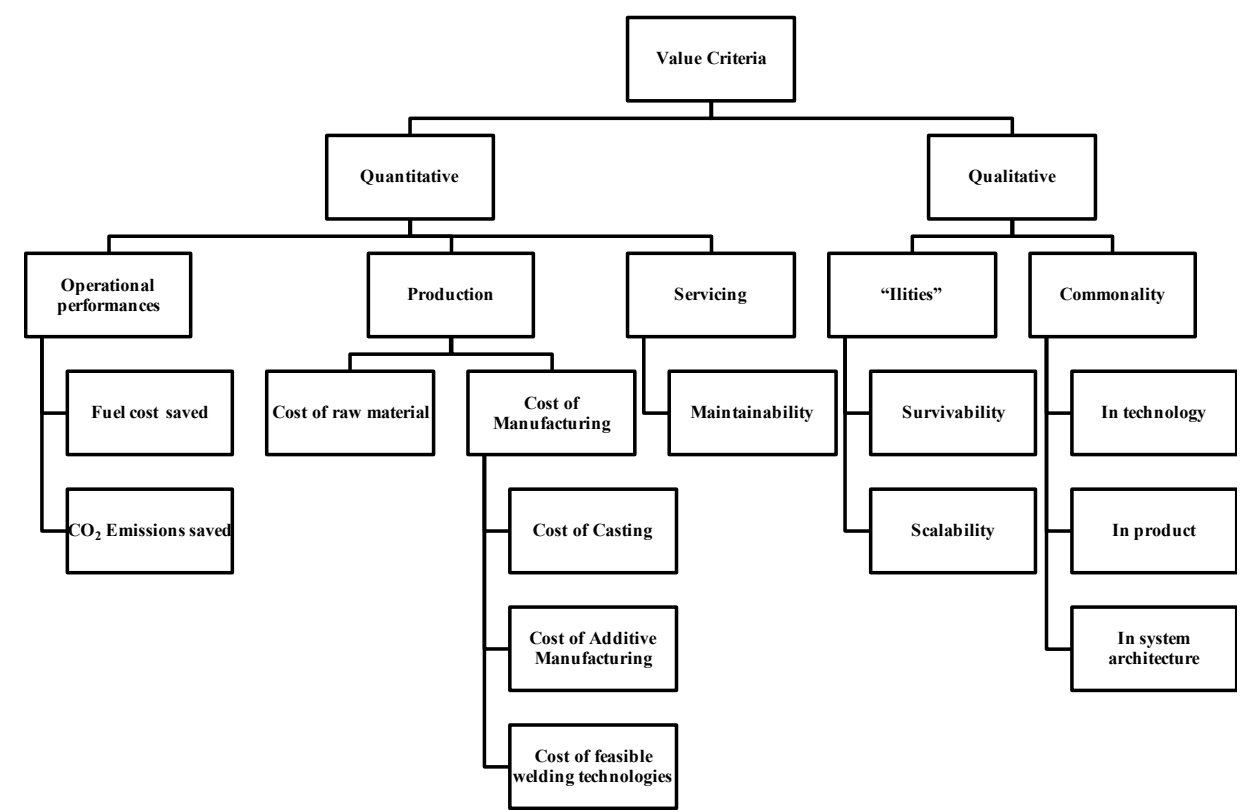

Figure 1. Value criteria identified in the study 
In the TRS study, both families of criteria have been taken into consideration for quantification. The output of early simulations has been directly used as input for the computation of the quantitative criteria by the development of specific functions. The computation of qualitative criteria is instead based on the possibility to access specific databases to compute the value of categorical variables. The following Table 1 describes how the quantitative value criteria have been computed in the TRS case, and how qualitative value criteria can be computed based on data availability. The Table lists the input considered either from simulation or external input, and the quantification method applied.

Table 1. Quantitative and qualitative value criteria considered in the TRS case

\begin{tabular}{|c|c|c|c|}
\hline \multicolumn{4}{|c|}{ QUANTITATIVE VALUE CRITERIA } \\
\hline Criteria & Input from simulation & External data-source & Specific Methods \\
\hline Fuel cost saved & - TRS mass & $\begin{array}{l}\text { - Aircraft fuel consumption model (ICAO) } \\
\text { - Aircraft weight-fuel consumption relation } \\
\text { - Expected life } \\
\text { - Cost of fuel }\end{array}$ & - Regression analysis on ICAO data \\
\hline CO2 emission saved & - TRS mass & - CO2 per kg of fuel (ICAO) & - Linear relation with fuel reduction \\
\hline Cost of raw material & - TRS mass & - Percentage of scrap from production & \\
\hline Cost of Casting & $\begin{array}{l}\text { - TRS mass } \\
\text { - Cube surface area } \\
\text { - Shape complexity }\end{array}$ & $\begin{array}{l}\text { - Casting practice database } \\
\text { - Plant and overhead costs estimates }\end{array}$ & - Activity-based costing \\
\hline $\begin{array}{l}\text { Cost of Additive } \\
\text { Manufacturing }\end{array}$ & - TRS mass & $\begin{array}{l}\text { - Additive manufacturing practices } \\
\text { - Plant and overhead costs estimates }\end{array}$ & - Activity-based costing \\
\hline $\begin{array}{l}\text { Cost of feasible welding } \\
\text { technologies }\end{array}$ & $\begin{array}{l}\text { - Weld length } \\
\text { - Weld thickness }\end{array}$ & $\begin{array}{l}\text { Welding technology capabilities } \\
\text { (EWB/TIG/Plasma/LBW) }\end{array}$ & $\begin{array}{l}\text { - Regression analysis } \\
\text { - Activity based costing }\end{array}$ \\
\hline Maintenability & - TRS mass & Life-limited parts model (Seemann et al., 2010) & Data mining on maintenance database \\
\hline \multicolumn{4}{|c|}{ QUALITATIVE VALUE CRITERIA } \\
\hline Criteria & Proxy parameters & Data to be accessed & Method to be applied \\
\hline Survivability & $\begin{array}{l}\text { Component behaviour in relation to: } \\
\text { - Unexpected higher temperature } \\
\text { - Fly into ash cloud } \\
\text { - Ice formation }\end{array}$ & $\begin{array}{l}\text { - Database of performances during tests } \\
\text { - Database of unexpected behaviour during } \\
\text { operation }\end{array}$ & Data mining \\
\hline Scalability & $\begin{array}{l}\text { - No.of component to modify if engine } \\
\text { diameter changes } \\
\text { - Efficiency of components in case of } \\
\text { engine weight change }\end{array}$ & $\begin{array}{l}\text { - Number of constraint in CAD models } \\
\text { - Tolerances and critical level in FEA }\end{array}$ & - Finite element analysis \\
\hline Commonality in technology & $\begin{array}{l}\text { \% of reuse of: } \\
\text { - Welding fixtures } \\
\text { - Qualified welding } \\
\text { - Tested material } \\
\text { - TRL level of technology }\end{array}$ & $\begin{array}{l}\text { - Database of qualified welding } \\
\text { - Database of tested material }\end{array}$ & - Data mining \\
\hline Commonality in product & $\begin{array}{l}\text { - \% features shared with other } \\
\text { components } \\
\text { - \% of raw material already in use }\end{array}$ & $\begin{array}{l}\text { - Database of used features } \\
\text { - Database of material used }\end{array}$ & - Database search \\
\hline $\begin{array}{l}\text { Commonality in system } \\
\text { architecture }\end{array}$ & $\begin{array}{l}\text { - Engine by-pass ration } \\
\text { - Engine overall pressure ratio } \\
\text { - Engine thrust to weight ration } \\
\text { - Engine electrical generation }\end{array}$ & - Engines performances and feature database & - Database search \\
\hline
\end{tabular}

\subsection{Definition of sustainability criteria and indicators}

To understand how a design solution influence social- and environmental sustainability aspects, and vice versa, it is necessary to identify which socio-ecological indicators that are relevant for a product throughout its whole lifecycle. When these indicators are identified there need to be an understanding of the correlation and the relationships between the sustainability indicators and the VDD criteria, as 
well as, the sustainability indicators and the design variables, to be able to develop ML algorithms and support design analysis.

In previous research sustainability criteria have been developed for the case company's products and processes, a so-called sustainability design space (Hallstedt, 2017). The sustainability design space as described by (Hallstedt, 2017) consists of three parts: i) Strategic Sustainability Criterion (SSC). The ideal long-term sustainability target and something to strive for is based on a rigorous definition of sustainability using overarching sustainability principles at the basis of a backcasting perspective (Missimer, 2015; Broman and Robèrt, 2017); ii) Tactical Sustainability Design Guideline (TSDG). The prioritized sustainability aspect that supports development towards the related long-term strategic sustainability criterion; iii) Sustainability Compliance Index (SCI). A metric that states the levels of compliance for each of the strategic sustainability criteria as a means to operationalize the use of the criteria strategically and tactically. The three parts SSC, TSDG and SCI are used together, where the SSC enables a stable definition of what is considered sustainable, e.g., no critical materials used according to the critical material lists. In line with Arena et al. (2009), these criteria need also to be measurable in order to be made operable for a company. A challenge is that operable metrics need to be applied in a more detailed context. The TSDG, e.g., reduces (in \%) critical materials for product components and/or its production, constitutes a necessary description of the sustainability aspects in a comparison of alternative design solutions. To assess to what degree a product concept performs in relation to a sustainable solution, an SCI has been developed (Hallstedt, 2017), consisting of qualitative sustainability levels: 9, 6, 3, 1 .

To have a full picture of the most important sustainability aspects of a product lifecycle, the SSC's need to be identified for each life-cycle phase with an eye to each of the eight sustainability principles. For the case company, long-term SSC's were identified as potential contributions to a misalignment of sustainability principles for each life-cycle phase. In total 43 SSC's were identified and examples of these are presented in Hallstedt (2017).

To cover a full picture of the sustainability impact of, for example, alloys' extraction and acquisition, information about restricted chemical usage, land degradation, energy usage, and violations of human's needs are important factors for decision making. However, detailed information and data in the early design phases from suppliers are very difficult to get, e.g., data regarding usage of materials that contain or result in chemicals that are included in the REACH-candidate list (European Commission, 2006); and, data regarding raw materials and chemicals and/or its manufacturing sites used that cause physical degradation of the environment. These types of sustainability issues can change and be improved later in a dialogue session with the suppliers. Instead, the so-called leading criteria divided into SCI levels for each life-cycle phase from the Sustainability Design Space is developed and selected to represent the most important sustainability aspects that can be accomplished within the time-constrained early design situation. The leading criteria support the product design team in what to prioritize when doing a first sustainability assessment for guiding decisions and they give enough guidance for the product design team to down-select a concept solution (Jaghbeer et al., 2017). The characterizations of the leading criteria are: i) data and information availability for the SCI judgement; ii) coverage of sustainability dimensions (social, environmental and economic/business perspectives); iii) aspects that affect the concept design directly or indirectly and that will be hard to change later on (or more costly). For each leading criteria sustainability indicators have been defined. (Hallstedt and Isaksson, 2017). In Table 2 the sustainability indicators for the case company, representing early life cycle phases of a product, are presented. The indicators are defined as measurements or facts (qualitative or quantitative) that indicate the state or level of the leading criteria. A suggested interval from acceptable to minimum level (worse state) including a target value for the case company has been suggested for each leading criterion. These intervals are guided by information and data found in documents such as sustainability reporting guidelines, environmental sustainability index report, strategies and guidelines from Advisor Council for Aviation Research and Innovation in Europe (ACARE, 2011). 
Table 2. Indicators for each leading criterion at the case company. A first suggested interval, from acceptable to minimum level (worse state) including a target value, for the case company is presented

\begin{tabular}{|c|c|c|c|}
\hline Life cycle & Leading criteria highlights & Indicators & Suggested intervals \\
\hline $\begin{array}{l}\text { Raw materials acquistition } \\
\text { and extraction }\end{array}$ & Critical materials & $\begin{array}{l}\text { Critical materials: } \mathrm{SCl} \text { score for } \\
\text { alloys }\end{array}$ & $\begin{array}{l}\text { Target: SCI level 6-9; any SCI score } \\
\text { Acceptable: SCIlevel 1-3 \& SCl score 0-40 } \\
\text { Minimum: SCI level 1: SCI score } 76\end{array}$ \\
\hline \multirow{5}{*}{ Production } & i) Recycled materials & $\begin{array}{l}\% \text { of materials used that are } \\
\text { recycled input materials }\end{array}$ & $\begin{array}{l}\text { Target: } 100 \% ; \\
\text { Acceptable: } 50 \% \\
\text { Minimum level: } 25 \% \text { (worste case) }\end{array}$ \\
\hline & ii) Scrap recyclability & Recycling rate of scrap (\%) & $\begin{array}{l}\text { Target: } 100 \% ; \\
\text { Acceptable: } 92 \% \\
\text { level: } 80 \% \text { (worste case) }\end{array}$ \\
\hline & iii) Risk of remanufacturing & Robustness index & $\begin{array}{l}\text { Target: No } \\
\text { Acceptable: yes, 20\% } \\
\text { Minimum level: Yes, more than 20\% (worste } \\
\text { case) }\end{array}$ \\
\hline & $\begin{array}{l}\text { iv) Emmissions, waste products } \\
\text { and chemicals listed in } \\
\text { REACH/IAEG lists }\end{array}$ & $\begin{array}{l}\text { Numbers of chemicals/ } \\
\text { hazardous materials } \\
\text { used/generated in the } \\
\text { production that are included in } \\
\text { the REACH and IAEG lists. }\end{array}$ & $\begin{array}{l}\text { Target: No } \\
\text { Acceptable: yes, 5\% } \\
\text { Minimum level: Yes, more than 5\% (worste } \\
\text { case) }\end{array}$ \\
\hline & v) Health and safety & $\begin{array}{l}\text { Number of injuries, risk of } \\
\text { exposure, leakages }\end{array}$ & $\begin{array}{l}\text { Target: } 0 \text { (no chemicals/materials in REACH or } \\
\text { IAEG lists) } \\
\text { Acceptable: } 0 \text { REACH candidate (no } \\
\text { materials/substances from production sites in } \\
\text { the REACH-candidate list, but } \\
\text { chemicals/materials included in the IAEG list } \\
\text { occur. } \\
\text { Minimum level: } 1 \text { or more substances included } \\
\text { in REACH list }\end{array}$ \\
\hline Distribution & $\begin{array}{l}\text { Risk of being exposed to really } \\
\text { dangerous substances. }\end{array}$ & $\begin{array}{l}\% \text { of health risk due to } \\
\text { exposure to dangerous } \\
\text { substances during distributuib } \\
\text { (per year) }\end{array}$ & $\begin{array}{l}\text { Target: } 0 \\
\text { Acceptable: } 0 \text { workrelated fatalities, } 2 \text { injuries, } \\
30 \text { lost days } \\
\text { Minimum level: } 0 \text { workrelated fatalities, } 4 \\
\text { injuries, } 60 \text { lost days }\end{array}$ \\
\hline \multirow{2}{*}{ Use and Maintenance } & i) Optimized product weight & $\begin{array}{l}\text { Weight reduction (for each } \\
\text { component) in } \% \text { compared to } \\
\text { previous solution }\end{array}$ & $\begin{array}{l}\text { Target: } 30 \% \text { weight reduction } \\
\text { Acceptable: } 15 \% \\
\text { Minimum level: } 5 \%\end{array}$ \\
\hline & ii) No noise to the surroundings & $\begin{array}{l}\text { Noise level reduction in } \% \\
\text { compared to previous solution }\end{array}$ & $\begin{array}{l}\text { Target: } 65 \% \text { reduction of noise } \\
\text { Acceptable: } 50 \% \text { reduction of noise } \\
\text { Minimum level: } 10 \%\end{array}$ \\
\hline End of Life & $\begin{array}{l}\text { All valuable materials/ } \\
\text { components are returned to the } \\
\text { value chain for remanufacturing } \\
\text { and recycling }\end{array}$ & $\begin{array}{l}\% \text { of components possible to } \\
\text { remanufacture and \% of } \\
\text { components that can be } \\
\text { recycled }\end{array}$ & $\begin{array}{l}\text { Target: } 100 \% \text { of components remanufactured \& } \\
95 \% \text { recycled } \\
\text { Acceptable: } 90 \% \text { of components } \\
\text { remanufactured } \& 90 \% \text { recycled } \\
\text { Minimum: } 85 \% \text { of components remanufactured } \\
\& 85 \% \text { of components recycled. }\end{array}$ \\
\hline
\end{tabular}

\subsection{Machine learning algorithm approach and application}

Despite the fact that computational tools and methods have been developed to support design engineers in decision making in early phases, the design of aircraft still remains complex due to multidisciplinary objectives, resulting in long project times from the conceptual phase to the product delivery (Min et al., 2017). For instance, simulations can take even weeks depending on the complexity of the problem of interest. Furthermore, multi-disciplinary analysis includes several tasks which may require a large number of simulations (hundreds or thousands). Therefore, there is a need to speed up the procedure of analysis. This is where machine learning plays a key role to build approximation models, also called supervised regression models or surrogate models, that can mimic the original system in order to minimise simulations and cost needed to investigate the design space.

In the design of aircraft, surrogate models have been used widely to approximate the expensive simulation models (Min et al., 2017). The generation of approximation models requires a dataset of inputs and known outputs. The known outputs are produced from simulations. Many studies have proven the effectiveness use of surrogate models to reduce computational cost for design optimization, design space explorations and sensitivity analysis. For instance, Huang et al. (2011), have built a surrogate model that approximates the computational mechanical analysis of engine components to reduce the computational cost. Jeong et al. (2005), have used data mining approaches for aerodynamic design space to identify the effect of design 
parameters on design objectives. Here information helped design engineers to find out the final design from non-dominated solutions of multi-objective problems. Furthermore, it also helped to screen the design space and to identify the rationale of the better performances of the optimal solution (Jeong et al., 2005). Mack et al. (2007), presented a use case about a compact liquid rocket radial turbine using surrogate models for design optimization to maximize the turbine efficiency while minimizing the turbine weight. Concerning the TRS case simulation data from design have been used to build surrogate models using linear regression, support vector machine, and tree models (i.e. M5P, Random Forests) to explore the design space (Dasari et al., 2015). The previously identified value and sustainability criteria became part of a unique dataset including simulation data from design of experiments (DOE). The dataset encompassed both quantitative and qualitative data. The data available in the datasets were then used to construct surrogate models to analyse the relationships and trends between the multiple parameters for a multi-disciplinary exploration of the TRS design space.

\subsection{The model-based approach for value and sustainability assessment enabled by the use of machine learning methods}

This subsection presents the application of the integrated approach in the case study coupling value and sustainability assessment to the results of DOE. Machine learning algorithms have been applied both with the descriptive and prescriptive goal to enable extensive multi-disciplinary design space exploration while sensibly reducing the time needed for the design analysis.

Figure 2 shows the process of the ideal integrated scenario has emerged from the empirical study. Different models are run in a concurrent fashion and have achieved different levels of development and application. Figure 2 shows in green the models that have been fully implemented in the TRS case study, in green with grey shadows those that are partially implemented and under test prior to further development, and in red with grey shadows the models under development, i.e. whose nature is still qualitative and are not automatically linked to the results of DOE analysis. On overall four main "stages" of the integrated scenario can be identified, namely: the DOE stage where " $n$ " design variations are simulated in computer-aided design environment; a "value assessment" stage, encompassing cost and performance value analysis and ilities quantification; a "sustainability assessment" stage including sustainability identification and sustainability models; and a "scenario integration" stage, where descriptive and predictive digital models are created and results are visualized.

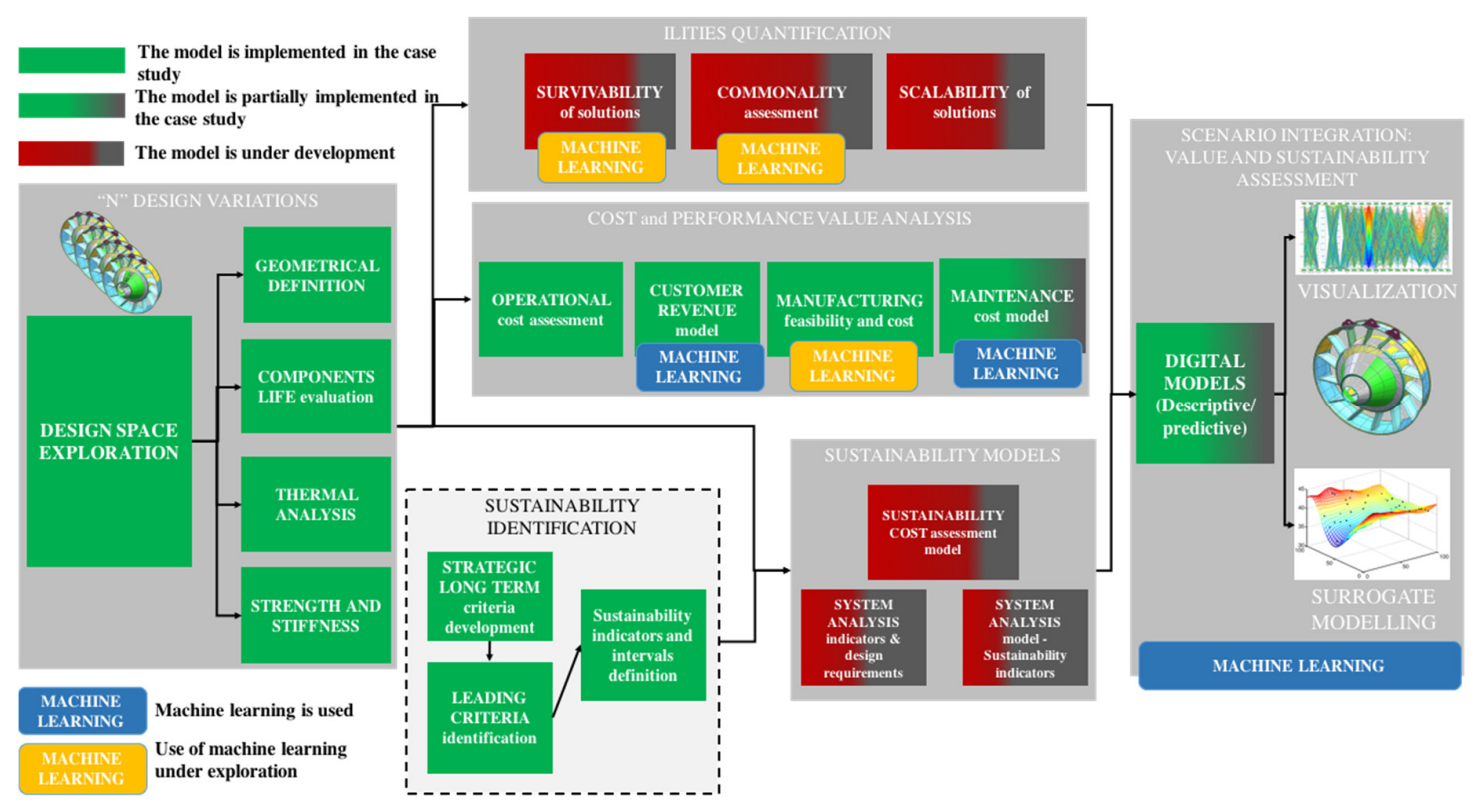

Figure 2. The model-based approach for value and sustainability assessment enabled by the use of machine learning methods 


\subsubsection{Generation of descriptive and predictive digital models in the TRS case study}

The first step of the approach consists in the generation of a high number of design variants (called design cases) in a computer-aided design environment, which engineering performances are evaluated through DOE. This stage requires high computational power using finite element analysis to simulate the design performances. Typically, hundreds of design cases can be simulated at this stage varying specific input parameters and the typical results obtained are the geometrical definition of the component, including mass and volume, the definition and quantification of the thermal areas, strength and stiffness assessment and component life evaluation. In the TRS example, those output from simulation serve as input for both value and sustainability modelling. Operational cost assessment, customer revenue models, manufacturing feasibility (and cost in particular related to the welding process) and maintenance cost models were run as quantitative value assessment models. The mass and volume of the different design cases, their geometrical dimensions, the length and thickness served as input for the quantitative value models. These data were complemented by the use of machine learning technique on external databases to derive specific predictive functions. This was the case, for instance, of the customer revenue models using ML to derive prediction about the fuel performances of aircraft under different operating conditions based on ICAO (2017) data, and of the maintenance cost model based on ML applied on aircraft maintenance databased (Seemann et al., 2010). An approach similar to that applied by Seemann et al. (2010) was potentially applicable for survivability and commonality assessment, although requiring historical data not available in the TRS case study.

Concurrently sustainability assessment was run on the design cases by first identifying strategic longterm and leading sustainability criteria so to define sustainability indicators and interval definition. The sustainability models were based on values characterized by qualitative assessments of the selected indicators. The overall intent of the approach was to integrate the final results into a digital model that could treat value and sustainability assessment as a natural result of the design of experiment, thus capable of comparing traditional engineering dimensions with value and sustainability aspects for hundreds of design cases in a restricted timeframe. The high quantity of data generated in the approach calls for a method to visualize the performances of different variables based on specific trade-off analysis run by engineers. The use of dynamic parallel diagrams emerged as a powerful tool to navigate through the design cases and generate a visual feedback on trends and trade-off between mechanical performances and value and sustainability scores, while at the same time allowing interactive analysis in the design team. Figure 3 shows an example of the visualization of the results with a dynamic parallel diagram. In the analysis, a selection of variables are included and the results are evaluated with respect to performance metrics such as Mass, Cost and Sustainability compliance.

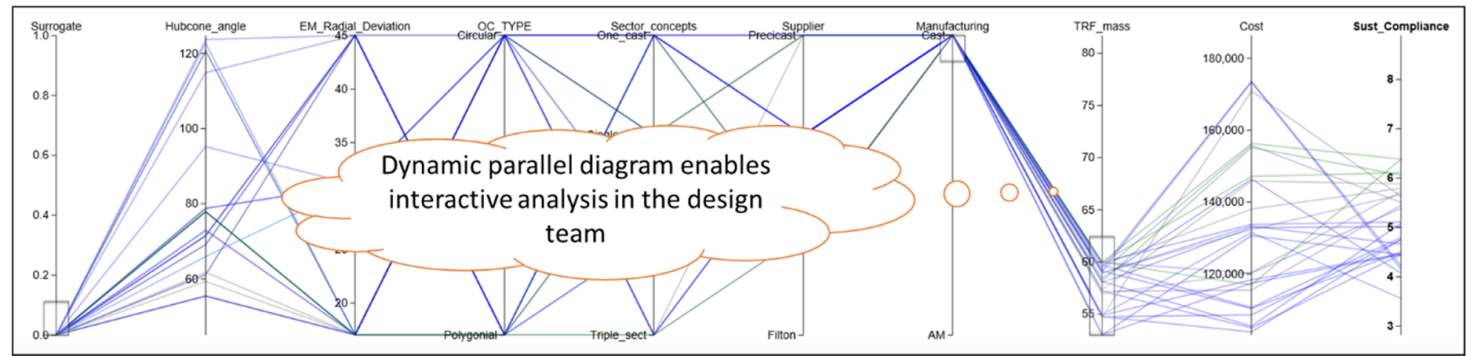

Figure 3. Illustration of dynamic parallel diagram

At this stage ML was applied to the available dataset encompassing also value and sustainability in order to derive surrogate models and response surfaces capable of predicting the multi-disciplinary performances of new design cases without the need to re-run simulations, thus saving consistent amount of time and resources in early design analysis. Furthermore, The advantage of using ML algorithms compared to traditional surrogate modelling techniques are the ability to include categorical data such as "supplier", "Manufacturing Method" etc. Figure 4 shows an example of the surrogate model derived from the TRS analysis, showing the increased number of design cases tested compared to those visualized in Figure 3. 


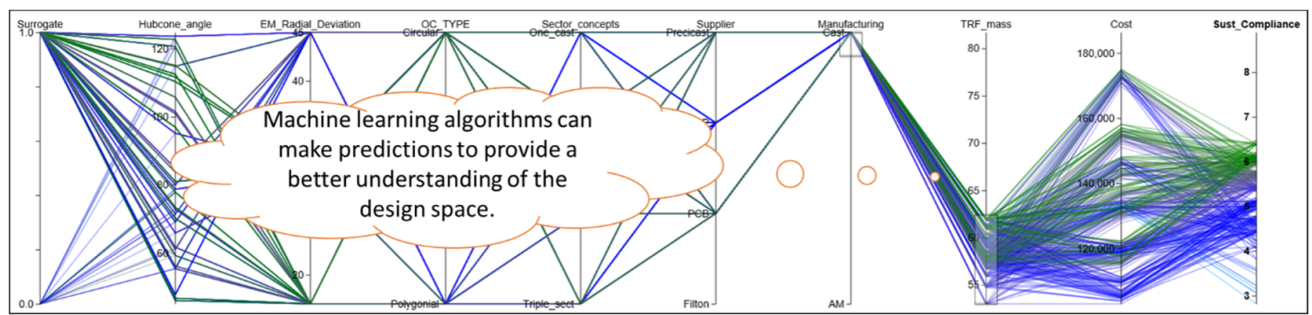

Figure 4. Illustration of how prediction based on ML complements the original assessment by providing a better understanding of the design space

\section{Concluding discussion}

Early phases of product development are sometimes described as "fuzzy" as they are characterized by incomplete information of both the product solution emerging, and the factual conditions wherein the product will be eventually used. As most companies adopt digital modelling techniques to create representations of a range of product solutions and uses simulation technologies to evaluate their anticipated behaviour, decision support needs to fit into such a work environment. The paper has presented a prescriptive approach toward exploiting the use of machine learning methods in combination with value and sustainability modelling to create a model-driven approach to support engineers in the early stages of complex design projects. The approach addresses the engineers' need to quickly and effectively investigate hundreds of possible designs configuration in the design space from a crossdisciplinary perspective. This drastically reduces the time for simulating design variations through the use of surrogate modelling. The result of the approach is a reduced set of potentially valuable design cases for more detailed analysis. In other words, the approach enables an initial multidisciplinary analysis of hundreds of design alternatives guiding the selection of the more promising solutions (indicatively four to five). The approach presented in Figure 2 is built on the work by Isaksson et al. (2015) initially providing a descriptive analysis of the industrial needs and challenges about the integration of value and sustainability in early design, and it is part of a larger research initiative aiming to the development of an integrated model-driven methodology for early design decision support. The application in the TRS case study was an intermediate step towards the final development of the methodology, run to test the applicability and effectiveness of the proposed model-based approach in a limited scenario. For this reason, some of the steps of the methodology described are under development. A number of research challenges still need to be addressed in these areas:

- Translating and calculating sustainability indicators to cost or return on investment (see Hallstedt et al., 2015). An introductory approach for identifying the relationship between one of the sustainability indicators, SCI score for alloys, design variables (number of vanes) and cost for one design study has been developed, but is not presented in this paper.

- Correlation studies and system analysis studies between sustainability indicators and value criteria. A better understanding is needed of how and which sustainability indicators and value criteria are correlated, e.g. fuel cost saved, $\mathrm{CO} 2$ emission saved, cost of raw material, commonality in product, commonality in production.

- Correlation studies and system analysis studies between sustainability indicators and design requirements. The need is having a better understanding of the relationships and the influences between sustainability indicators and design requirements to support identifying which sustainability requirements to investigate in the early design phase.

Conclusions can be drawn concerning the verification of the usability and applicability of the approach in the case study, presented in Section 3:

- The approach allows the concurrent multidimensional analysis of design cases complementing mechanical simulation results with value and sustainability assessment. Visualizations and surrogate modelling allowed the considerations of aspects not available in traditional DOE results, thus expanding the design space considerations.

- Machine learning algorithms allow dealing with both qualitative and quantitative data in unique models allowing prediction based on both categorical and numerical variables. This has been 
especially relevant for the integration of sustainability assessment in the DOE results prior to the visualization of the results with dynamic parallel diagrams.

- The approach does not integrate a method to quantify the results reliability other than the precision of the ML algorithm used. The integration of the quantification of the uncertainty embedded in the assumption used in value and sustainability assessment is subject to further research.

\section{Acknowledgments}

The research leading to these results has received financial support by the Swedish Knowledge and Competence Development Foundation (Stiftelsen för kunskaps- och kompetensutveckling) through the Model Driven Development and Decision Support research profile at Blekinge Institute of Technology.

\section{References}

ACARE (2011), Fligthpath 2050 - Europe's vision for aviation. Report of the high level group on aviation research, Advisory Council for Aeronautics Research in Europe, European Commission.

Akhavian, R. and Behzadan, A.H. (2013), "Knowledge-based simulation modeling of construction fleet operations using multimodal-process data mining”, Journal of Construction Engineering and Management, Vol. 139 No. 11. https://doi.org/10.1061/(ASCE)CO.1943-7862.0000775

Arena, M., Ciceri, N.D., Terzi, S., Bengo, I., Azzone, G., Garetti, M. (2009), “A state-of-the-art of industrial sustainability: definitions, tools and metrics", International Journal of Product Lifecycle Management, Vol. 4 No. 1, pp. 207-251. https://doi.org/10.1504/IJPLM.2009.031674

Avison, D.E., Lau, F., Myers, M.D. and Nielsen, P.A. (1999), “Action research”, Communications of the ACM, Vol. 42 No. 1, pp. 94-97. https://doi.org/10.1145/291469.291479

Bertoni, A., Amnell, H. and Isaksson, O. (2015b), "Value modelling in aerospace sub-system design: linking quantitative and qualitative assessment", 20th International Conference on Engineering Design, ICED15, Milan, Italy, The Design Society.

Bertoni, A., Bertoni, M., Panarotto, M., Johansson, C. and Larsson, T.C. (2016), "Value-driven product service systems development: Methods and industrial applications", CIRP Journal of Manufacturing Science and Technology, Vol. 15, pp. 42-55. https://doi.org/10.1016/j.cirpj.2016.04.008

Bertoni, A., Larsson, T., Larsson, J. and Elfsberg, J. (2017), "Mining data to design value: A demonstrator in early design", 21st International Conference on Engineering Design (ICED17).

Bertoni, M., Eres, H. and Isaksson, O. (2011), "Criteria for assessing the value of Product Service System design alternatives: an aerospace investigation", Functional thinking for value creation, Proceedings of the 3rd CIRP International Conference on Industrial Product Service Systems, pp. 141-146. https://doi.org/10.1007/978-3642-19689-8_26

Bertoni, M., Hallstedt, S. and Isaksson, O. (2015a), "A model-based approach for sustainability and value assessment in the aerospace value chain", Advances in Mechanical Engineering, Vol. 7 No. 6. https://doi.org/10.1177/1687814015590215

Blessing, L.T. and Chakrabarti, A. (2009), DRM, a Design Research Methodology, Springer Science \& Business Media. https://doi.org/10.1007/978-1-84882-587-1

Broman, G.I., Robèrt, K.-H., (2017), “A Framework for Strategic Sustainable Development”, Journal of Cleaner Production, Vol. 140 No. 1, pp. 17-31. https://doi.org/10.1016/j.jclepro.2015.10.121

Coughlan, P. and Coghlan, D. (2002), “Action research for operations management”, International Journal of Operations \& Production Management, Vol. 22 No. 2, pp. 220-240. https://doi.org/10.1108/01443570210417515

Dasari, S.K., Lavesson, N., Andersson, P. and Persson, M. (2015), "Tree-based response surface analysis", International Workshop on Machine Learning, Optimization and Big Data, Springer, Cham, pp. 118-129. https://doi.org/10.1007/978-3-319-27926-8 11

European Commission (2006), "Regulation (EC) No 1907/2006 of the European parliament and of the council of 18 December 2006 concerning the Registration, Evaluation, Authorisation and Restriction of Chemicals", Official Journal of the European Union, Vol. 49.

Giudice, F., La Rosa, G. and Risitano, A. (2005), "Materials selection in the life-cycle design process: a method to integrate mechanical and environmental performances in optimal choice", Materials \& Design, Vol. 26 No. 1, pp. 9-20. https://doi.org/10.1016/j.matdes.2004.04.006

Hallstedt, S.I. and Isaksson, O. (2017), "Material criticality assessment in early phases of sustainable product development", Journal of Cleaner Production, Vol. 161, pp. 40-52. https://doi.org/10.1016/j.jclepro.2017.05.085 
Hallstedt, S.I. (2017), "Sustainability criteria and sustainability compliance index for decision support in product development", Journal of Cleaner production, Vol. 140, pp. 251-266. https://doi.org/10.1016/j.jclepro.2015.06.068

Huang, Z., Wang, C., Chen, J. and Tian, H. (2011), "Optimal design of aeroengine turbine disc based on kriging surrogate models", Computers \& Structures, Vol. $89 \quad$ No. 1, pp. 27-37. https://doi.org/10.1016/j.compstruc.2010.07.010

ICAO (2017), ICAO Carbon Emissions Calculation Methodology, Version 10. [online] Available at: https://www.icao.int/environmental-protection/CarbonOffset/Documents/Methodology\%20ICAO\%20Carbon \%20Calculator_v10-2017.pdf (accessed 19.10.2017).

Isaksson, O., Bertoni, M., Hallstedt, S. and Lavesson, N. (2015), "Model Based Decision Support for Value and Sustainability in Product Development", 20th International Conference on Engineering Design (ICED), Milan, The Design Society.

Jaghbeer, Y., Hallstedt, S.I., Larsson, T. and Wall, J. (2017), "Exploration of simulation-driven support tools for sustainable product development", Procedia CIRP, Vol. 64, pp. 271-276. https://doi.org/10.1016/j.procir.2017.03.069

Jeong, S., Chiba, K. and Obayashi, S. (2005), "Data Mining for Aerodynamic Design space”, JACIC, Vol. 2 No. 11, pp. 452-469. https://doi.org/10.2514/1.17308

Mack, Y., Goel, T., Shyy, W. and Haftka, R. (2007), "Surrogate model-based optimization framework: a case study in aerospace design", In: Shengxiang Yang, S., Ong, Y.-S. and Jin, Y., Evolutionary computation in dynamic and uncertain environments, pp. 323-342. https://doi.org/10.1007/978-3-540-49774-5_14

McManus, H., Richards, M., Ross, A. and Hastings, D. (2007), "A Framework for Incorporating "ilities" in Tradespace Studies”, AIAA Space, Vol. 1, pp. 941-954. https://doi.org/10.2514/6.2007-6100

Min, A.T.W., Sagarna, R., Gupta, A., Ong, Y.S. and Goh, C.K. (2017), "Knowledge Transfer Through Machine Learning in Aircraft Design", IEEE Computational Intelligence Magazine, Vol. 12 No. 4, pp. 48-60. https://doi.org/10.1109/MCI.2017.2742781

Missimer, M. (2015), Social sustainability within the framework for strategic sustainable development, PhD thesis, Blekinge Institute of Technology.

Queipo, N.V., Haftka, R.T., Shyy, W., Goel, T., Vaidyanathan, R. and Tucker, P.K. (2005), "Surrogate-based analysis and optimization", Progress in Aerospace Sciences, Vol. 41 No. 1, pp. 1-28. https://doi.org/10.1016/j.paerosci.2005.02.001

Quintana-Amate, S., Bermell-Garcia, P., Tiwari, A. and Turner, C.J. (2017), "A new knowledge sourcing framework for knowledge-based engineering: An aerospace industry case study", Computers \& Industrial Engineering, Vol. 104, pp. 35-50. https://doi.org/10.1016/j.cie.2016.12.013

Ross, A.M., Hastings, D.E., Warmkessel, J.M. and Diller, N.P. (2004), "Multi-attribute tradespace exploration as front end for effective space system design”, Journal of Spacecraft and Rockets, Vol. 41 No. 1, pp. 20-28. https://doi.org/10.2514/1.9204

Schulte, J. and Hallstedt, S. (2017), "Challenges and preconditions to build capabilities for sustainable product design”, 21st International Conference on Engineering Design (ICED17), Vol. 1 No. DS87-1, Vancouver, pp. 1-10, The Design Society.

Seemann, R., Langhans, S., Schilling, T. and Gollnick, V. (2010), "Modeling the life cycle cost of jet engine maintenance", 60. Deutscher Luft- und Raumfahrtkongress (DLRK), 27.-29. September 2011, Bremen.

Shan, S. and Wang, G.G. (2010), "Survey of modeling and optimization strategies to solve high-dimensional design problems with computationally-expensive black-box functions", Structural and Multidisciplinary Optimization, Vol. 41 No. 2, pp. 219-241. https://doi.org/10.1007/s00158-009-0420-2

Sobek, D.K., Ward, A.C. and Liker, J.K. (1999), "Toyota's principles of set-based concurrent engineering”, Sloan Management Review, Vol. 40 No. 2, pp. 67-83.

Steiner, F. and Harmon, R. (2009), "The impact of intangible value on the design and marketing of new products and services: An exploratory approach”, Management of Engineering \& Technology, 2009. PICMET 2009. Portland International Conference, IEEE, pp. 2066-2079. https://doi.org/10.1109/PICMET.2009.5261890

Verhagen, W.J., Bermell-Garcia, P., van Dijk, R.E. and Curran, R. (2012), “A critical review of Knowledge-Based Engineering: An identification of research challenges”, Advanced Engineering Informatics, Vol. 26 No. 1, pp. 5-15. https://doi.org/10.1016/j.aei.2011.06.004

Dr.-Ing. Alessandro Bertoni, Assistant Professor / Senior Lecturer

Blekinge Institute of Technology, Mechanical Engineering

Campus Gräsvik, 37179 Karlskrona, Sweden

Email: alessandro.bertoni@bth.se 